\title{
Проблемы и перспективы функционирования банковской системы в регионах России
}

Ю.А. МАКЛАКОВА, НИФИ при Министерстве финансов, МГУ им. М.В. Ломоносова, Москва. E-mail: yulalmaklakova@yandex.ru

Аннотация. Современные исследователи регионального банковского бизнеса часто пользуются понятием «региональный банк», которого нет в законодательстве, редко обращая внимание на социальную функцию и, в целом, особенности развития регионального банкинга. Между тем в регионах, особенно удаленных, специфика клиентуры (большая доля мелких клиентов, часто - плохо владеющих современными цифровыми технологиями, с низким уровнем финансовой грамотности), имеющиеся инфраструктурные ограничения предъявляют особые требования к банкингу, которые попытался выделить автор. Сложившаяся в последние годы тенденция к диджитализации ориентирует банкинг преимущественно на возможности Центрального административного региона без учета нужд банковской периферии. «Зачистка» банковского сектора, которая происходит в основном за счет его региональной сети, ведет к сокращению количества банков и их подразделений, переводу банковских продуктов и услуг в online-режим, что, по мнению автора, не является оптимальным решением проблемы устойчивости банковского сектора. На основе изучения отечественного и зарубежного опыта, а также интервьюирования экспертов, автор формулирует ряд рекомендаций в части улучшения качества деятельности региональной банковской сети. Главные положения и выводы статьи могут быть предложены государственным органам управления и менеджменту банков.

Ключевые слова: региональные банки; развитие региональной банковской сети; зарубежный опыт регионального банкинга; проблемы и перспективы регионов России; финансовая грамотность; диджитализация; «зачистка» (сокращение) банковского сектора

\section{Введение}

В результате набирающей обороты диджитализации банковского бизнеса (в России, как и во всем мире) многие отечественные банки, в том числе ключевые игроки рынка, закрывают свои региональные подразделения. При этом в офисах клиентам предлагаются преимущественно высокодоходные продукты и услуги, а операции, не способные приносить существенной прибыли, переводятся в online-режим. Так, ПАО «Сбербанк» в рамках стратегии переформатирования сети, запущенной в 2010 г., только за последние пять лет закрыл около 4 тыс. отделений и офисов, львиная доля которых была расположена в сельской 
местности. ПАО «Россельхозбанк» с 2013 г. ликвидировал около $20 \%$ отделений. Однако, по мнению автора, низкая рентабельность отдельных подразделений не может служить оправданием лишения граждан и бизнеса доступа к банковским услугам. Миссию банков следует описывать с точки зрения наличия 4c: смысл, содержание, специфика, социальный аспект [Маклакова, 2016]. Иными словами, основная цель функционирования банков должна быть сосредоточена на соблюдении принципов клиентоориентированности и социальной направленности [Журавлёва, 2015].

Учитывая низкий уровень финансовой грамотности населения в большинстве регионов России, банкам, исходя из их системных функций, необходимо обращать внимание не только на выгоду, но и на потребности граждан, многие из которых не готовы к самообслуживанию с помощью гаджетов.

Тема регионального банкинга уже давно находит широкое освещение в научной и учебной литературе, не раз становилась повесткой отраслевых конференций различного уровня, включая международный [Fiorentino, 2009]. Большинство исследователей в своих работах делают акцент на формулировании определения и сущности региональных банков для того, чтобы дать свои рекомендации институтам банковского сектора (Банк России, Ассоциация российских банков и т.д.), в то время как в законодательстве понятие «региональный банк» до сих пор не закреплено. При этом социальной составляющей - одному из ключевых элементов банкинга, в исследованиях, профессиональном дискурсе уделяется совсем мало внимания. Несмотря на то, что сами банки постоянно заявляют о своей клиентоориентированности, в обозримом массиве публикаций автор не смогла найти работ, затрагивающих такие аспекты, как анализ нужд клиентов, их региональные особенности, финансовая грамотность клиентов банков и способность целевой аудитории быстро приспособиться к новым реалиям.

Между тем в цифровой экономике актуальной задачей научного сообщества и практиков становится создание новых продуктов или адаптация уже существующих предложений под специфику конкретной страны, компании или любого другого хозяйствующего субъекта. 
Целью исследования стало рассмотрение существенных особенностей ведения банковского бизнеса в регионах.

Региональные банки в данной статье понимаются как кредитные организации, осуществляющие основную часть своей деятельности за пределами Центрального федерального округа и предоставляющие услуги традиционного банкинга - кредитование, прием вкладов и расчетное банковское обслуживание, валютообменные операции и т.п. Как правило, региональные банки не занимаются нетиповыми банковскими операциями (доверительное управление денежными средствами и имуществом, работа с производными финансовыми инструментами и т.д.).

\section{Проблемы регионального банкинга}

В некоторых удаленных точках нашей страны доступ к банковским продуктам и услугам практически отсутствует ${ }^{1}$. К примеру, на территории всего Чукотского АО (территория 737 тыс. км², население - около 50 тыс. чел., плотность населения $-0,07$ чел./км²) банковские операции могут проводиться только через операционные офисы нескольких банков, в то время как данный вид подразделения кредитной организации имеет, согласно законодательству, ряд значительных ограничений (запрещено, например: осуществление операций по купле/продаже иностранной валюты; на обслуживание в операционном офисе могут быть переданы сделки, принятие риска на одного заемщика по которым не должно превышать 5\% капитала банка и др.). Стоит отметить, что число дополнительных офисов и операционных касс в Чукотском АО стало резко сокращаться с 2013 г., а самостоятельных банков в этом регионе не представлено ${ }^{2}$. Кроме того, отсутствие в регионе стабильной интернет-связи создает дополнительные трудности при обеспечении банковского обслуживания (рис. 1).

${ }^{1}$ Олени против банкиров // Информационный портал «Банки.py». URL: https://www. banki.ru/news/daytheme/?id=10532967 (дата обращения: 15.02.2019).

${ }^{2}$ Постановление Правительства Чукотского автономного округа от 21.06.2013 № 225. 


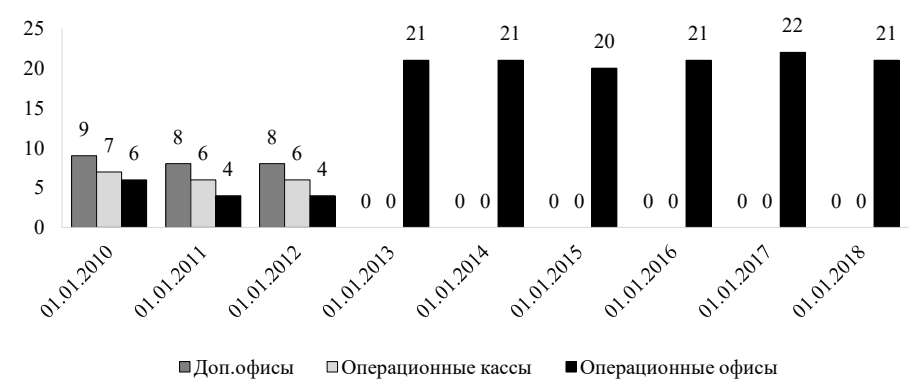

Источник: Банк России. URL: https://www.cbr.ru/statistics/pdko/lic/ (дата обращения: 24.05.2019).

Puc. 1. Динамика количества внутренних структурных подразделений действующих кредитных организаций (филиалов) в Чукотском АО в 2010-2018 гг.

В Республике Тыва (территория - 170 тыс. км², население - 321 тыс. чел.) зарегистрирован только один банк, ОАО АБ «Народный банк РТ», и работают филиалы Сбербанка, Россельхозбанка и АКБ «Связь-Банк». Это ограничивает клиентов в выборе оператора для зарплатных проектов, а низкий уровень конкуренции сказывается на условиях получения кредита и размещения средств на депозитах и вкладах (рис. 2).

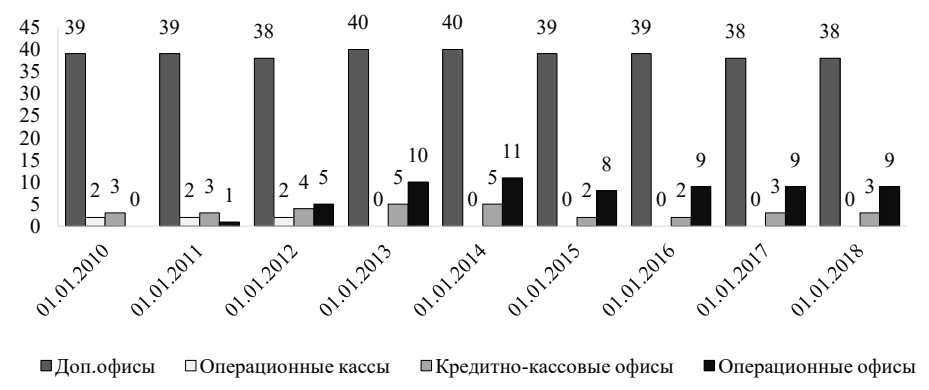

Источник: Банк России. URL: https://www.cbr.ru/statistics/pdko/lic/ (дата обращения: 24.05.2019).

Puc. 2. Динамика количества внутренних структурных подразделений действующих кредитных организаций (филиалов) в Республике Тыва в 2010-2018 гг.

Во многих других регионах, особенно в сельской местности, удаленной от финансовых центров, отсутствует комфортный доступ как физических, так и юридических лиц к банковским 
продуктам и услугам, включая кредитные, что подтверждают отдельные исследования [Кравец, Потапова, 2016]. В небольших городах и посёлках есть проблема плотности покрытия территории банковской сетью.

В 2016 г. на 100 тыс. чел. трудоспособных россиян приходилось 38 подразделений различных банков ${ }^{3}$. Для сравнения: в Канаде данный показатель равен 24,4 отделения на 100 тыс. человек, в Австралии - 30,7 отделений на 100 тыс., в Аргентине 13,4. Казалось бы, Россия лидирует, однако не стоит забывать, что проблема нашей страны - в неоднородном охвате населения банковскими услугами. Недоступность банковских услуг является сдерживающим фактором развития малого и среднего бизнеса и экономики в целом, а также приводит к неравенству возможностей у жителей таких регионов [Guiso, 2002]. Проблема не является сугубо российской - в разделе, посвященном международному опыту ведения регионального банковского бизнеса, данный вопрос будет рассмотрен более детально.

Доступность финансовых услуг можно условно разделить на три категории: доступность, возможность использования и качество услуг [Convery et al., 2003].

Д.В. Клешко и Р.А. Мусаев оценили корреляцию между количеством региональных банков, офисов и показателями финансовой доступности по трем критериям: количество банкоматов и подразделений действующих банков на 1 миллион трудоспособного населения, индикатор финансовой грамотности. И установили прямую зависимость между количеством региональных банков и уровнем финансовой доступности. По их мнению, сокращение числа региональных кредитных организаций отрицательно сказывается как на степени обеспечения населения финансовыми услугами, так и на финансовой грамотности [Клешко, Мусаев, 2016].

Центральный банк озабочен проблемами повышения надежности и эффективности работы банковского сектора, что сказывается на количестве банковских организаций в системе и в некоторых регионах. Банки, в свою очередь, стремятся перевести некоторые низкомаржинальные операции в онлайн-режим, чтобы

${ }^{3}$ Аналитический центр «НАФИ». https://nafi.ru/projects/finansy/uroven-dostupnostifinansovykh-uslug-v-rossiyskoy-federatsii/ (дата обращения: 24.05.2019). 
сократить количество офисов и уменьшить свои расходы по их обслуживанию (аренда помещений, покупка и эксплуатация оборудования, оплата труда персонала и т.д.). Но как это сказывается на банковском обслуживании в регионах? Мы решили выяснить это у самих банкиров.

К опросу были привлечены специалисты разных подразделений из банков Краснодара (население: 918145 чел.; площадь: 339 км²), Самары (население: 1163339 чел.; площадь: 541,4 км²), Керчи (население: 151025 чел.; площадь: 108 км²), Тольятти (население: 707408 чел.; площадь: 314 км²), Воронежа (население: 1054537 чел.; площадь: 6596 км²), Томска (население: 574002 чел.; площадь: 294 км²), Пучежа-Ивановская область (население: 7078 чел.; площадь: 6,41 км²). В качестве экспертов привлекались банковские служащие «Сбербанка», ВТБ, Россельхозбанка, Совкомбанка, АО «Воронеж» ${ }^{4}$ следующих должностей: специалист отдела HR, специалист, занимающийся прямыми продажами, операционист, маркетолог.

Экспертам было предложено ответить на вопросы анкеты в формате непринужденной беседы.

1. Работаете ли сейчас в банковской сфере?

- Если да - в каком банке какого региона?

- Если нет - в каком банке какого региона работали раньше?

2. Считаете ли Вы, что количество банков в регионе достаточно для покрытия спроса физических и юридических лиц?

3. Каким продуктам и услугам, на Ваш взгляд, население отдает предпочтение?

4. Какой вариант получения продуктов и услуг интересует население больше - online или offline?

5. Как Вы считаете, следит ли население Вашего региона за новостным фоном?

6. Были ли зафиксированы в Вашем регионе случаи отзыва лицензии у банков и как закрытие других кредитных организаций сказалось на работе Вашего офиса?

7. Были ли зафиксированы в Вашем регионе закрытия офисов крупных кредитных организаций и как это сказалось на работе Вашего офиса?

${ }^{4} 1506.2018$ г. у этого банка была отозвана лицензия. См. приказ ЦБР: URL: https://www. cbr.ru/press/pr/?file=15062018_084911ik2018-06-15t08_48_28.htm (дата обращения: 27.05.2019). 
Логично, что финансовая грамотность населения, как и готовность к обучению новым способам получения услуг через мобильные устройства, существенно варьирует не только в масштабах страны, но и одного региона, и даже населенного пункта, и зависит от образовательного уровня граждан, их возраста, психологических установок и т.д. Недооценка этих факторов, на наш взгляд, чревата потерей контакта банков с клиентами.

Для наиболее крупных городов, где нам удалось привлечь респондентов, а именно: в Краснодаре, Самаре, Воронеже, Тольятти, характерны следующие общие черты:

- население имеет широкий выбор кредитных организаций, поэтому закрытие некоторых из них не слишком сказывается на удовлетворенности спроса населения;

- население следит за масштабными событиями в экономике, но постоянного интереса не наблюдается;

- крупные игроки банковского бизнеса стремятся перевести в online-режим максимально большое количество операций, однако клиенты старшего поколения не хотят пользоваться приложениями удаленного интернет-доступа к банку, предпочитая лично посещать офис и получать там ответы на интересующие их вопросы в режиме непосредственного контакта с менеджером.

В разговоре с томским специалистом мы узнали об уникальной практике обслуживания деревень Томской области - с помощью передвижных мобильных офисов. Машина со специалистами и необходимым оборудованием приезжает на территорию деревни или села в определённые дни и предлагает населению банковские продукты и услуги. Таких «офисов на колесах» в данном регионе в 2016 г. было около 70. Это - прекрасный пример клиентоориентированного банкинга. На наш взгляд, практика мобильных офисов должна быть взята на вооружение во многих регионах России, где дисперсное расселение и уровень развития бизнеса делают нерентабельным содержание стационарных офисов, но эпизодический спрос на банковские услуги все же существует, и он должен быть удовлетворен без необходимости ехать в другой город.

Эксперт из Тольятти поделился с нами интересными рассуждениями о внедрении онлайн-услуг для населения. Стратегии крупных банков, входящих в список стратегически значимых 
организаций, ориентированы на диджитализацию услуг, в связи с чем клиентов активно обучают пользоваться мобильными приложениями. В офисах таких банков есть планшеты, которыми может бесплатно воспользоваться любой желающий с помощью специалиста или самостоятельно. В тольяттинские офисы ВТБ довольно часто обращаются пожилые люди. Они не имеют банковских приложений на собственных мобильных устройствах и совершают необходимые операции с помощью предлагаемых банком планшетов. Отвечая на вопрос № 4 анкеты, эксперт отметил, что клиенты всё еще отдают предпочтение физическим офисам. По его мнению, людям нравится приходить в банк и получать помощь специалиста, даже при условии активного использования online-приложений. Уверенные пользователи онлайн-услуг, согласно его оценкам, составляют около 30\% клиентов.

Большой удачей было найти респондента из совсем небольшого городка Пучежа, где мы смогли увидеть все аспекты изучаемой проблематики:

1) в городе очень небольшой выбор кредитных организаций (Сбербанк, Россельхозбанк, Совкомбанк);

2) не так давно Сбербанк стал закрывать в городе свои дополнительные офисы;

3) менеджеры центральных офисов, контролирующие банковскую деятельность, не осознают всю сложность внедрения новых банковских продуктов в малых городах;

4) для получения банковских услуг или продуктов люди вынуждены ездить в другой город (Иваново), находящийся в 150 км от Пучежа (на общественном транспорте дорога занимает около 2 часов в одну сторону);

5) в Пучеже проживает большое количество пенсионеров, которые с Интернетом «на вы» и предпочитают личное общение со специалистами. Даже имея пластиковые карты, они не хотят активно ими пользоваться - за деньгами приходят в банк лично. Наиболее популярный продукт - вклады.

«Зачистка» банковского сектора не отразилась в Пучеже на количестве банков (их как было, так и остается - три). В то же время локальный рынок банковских услуг сократился из-за закрытия дополнительных офисов, так как их содержание стало невыгодным. 
Изучая частные аспекты работы региональных кредитных организаций, мы обратились к трудам других авторов, пишущих на данную тему. Так, Мусаев и Клешко рассматривают интересные кейсы российских региональных банков, в которых высвечены вопросы банковского обслуживания. Авторы, в частности, сосредоточивают внимание на проблеме повышения финансовой грамотности. Например, на сайте $\mathrm{AO}$ «Черноморский банк развития и реконструкции» есть разделы, посвященные просвещению пользователей сайта по финансовым вопросам, часто возникающим у потенциальных и актуальных клиентов: что такое страхование вкладов? Как должны действовать заемщики при отзыве лицензии у банка и т.д. [Клешко, Мусаев, 2015].

ООО КБ «Кубань Кредит» практикует проведение семинаров и мастер-классов по различным вопросам финансовой грамотности для населения, собственников малого и среднего бизнеса, индивидуальных предпринимателей. ООО КБ «Кольцо Урала» занимается развитием сети мини-офисов в небольших населенных пунктах, где у людей нет широкого доступа к банковским продуктам и услугам. ПАО КБ «Уральский финансовый дом» развивает на базе своих отделений коворкинговые площадки, позволяющие встречаться предпринимателям для обмена опытом.

Отличным примером для подражания можно назвать ПАО Банк «Левобережный», являющийся не только крупным региональным банком, но и активно развивающий сеть продаж (более 60 дополнительных и операционных офисов в Западно-Сибирском регионе) параллельно с внедрением цифровых технологий (банк занял третье место по России в рейтинге Markswebb Rank \&Report по показателю daily banking (доступность услуг по дебетовой карте и получение информации в режиме online).

\section{Особенности функционирования регионального банковского бизнеса в Китае и Индии}

Кроме изучения ситуации в отдельных регионах России, мы решили обратиться к зарубежному опыту, чтобы понять, какие регулятивные решения и также частные идеи, реализованные в зарубежном банковском бизнесе, могут повысить эффективность банковского сектора Российской Федерации. Рассмотрим практику регионального банкинга в КНР и Индии, поскольку 
в данных странах уровень взаимодействия государства и банков схож с тем, что наблюдается в России.

Китайский банковский рынок отличают высокие темпы роста, жесткий государственный контроль и сильная концентрация банковского капитала. «Большая четверка» китайских банков исторически занимает олигополистическое положение на рынке. Через них проходит до половины всех финансовых потоков страны.

Изначально в Китае существовал только один банк, выполняющий роль и коммерческого банка, и центрального. Когда экономика Китая стала вставать на рыночные рельсы (1990-е годы), из одного государственного банка выделили четыре отраслевых (Торгово-промышленный, Сельскохозяйственный, Строительный и Банк Китая), которые также могут принимать депозиты и вести коммерческий банковский бизнес. При этом первоначальный банк стал выполнять роль центрального и получил название Народный банк Китая (People's Bank of China).

Финансовыми потоками в Китае в основном управляет государство, что обеспечивает сохранение доверия клиентов к банковской системе. Оптимизм инвесторов поддерживается также постоянным ростом китайской экономики и курса юаня 5 . В свою очередь постоянное увеличение объемов банковского кредитования под гарантии государства (как мера господдержки экономики), большая доля «замаскированных» кредитов, когда обычный заём отражается на балансе как инвестиционный инструмент, под который выделяются минимальные резервы, позволяют китайским банкам зарабатывать высокие прибыли.

Для нашего исследования опыт КНР представляет интерес с точки зрения развития регионального банкинга. Несмотря на то, что подразделения банков «большой четверки» присутствуют в каждом регионе страны, основу региональной банковской сети составляют многочисленные сельскохозяйственные и городские кредитные кооперативы, специализирующиеся на кредитовании малого бизнеса и сельских жителей. Все они создаются государством, исходя из потребностей конкретного региона (создание предприятий, направленных на оказание

${ }^{5}$ Иванов Ф. Банковская система Китая стала крупнейшей в мире //ИА «RNS»-2017, март. 
целевых услуг в регионах Китая) или с ориентиром на задачи властей (создание организаций для развития одного или нескольких целевых секторов). Нам представляется, что детальное изучение этого опыта может быть полезно для России.

Стоит заметить, что жесткий контроль государства не устраняет возможность появления значимых для банковского сектора КНР рисков. Один из них - это сверхконцентрация, угрожающая устойчивости системы. Кроме того, серьезной проблемой для Китая в последние годы стал теневой банкинг. В свое время власти закрывали на него глаза, считая его одним из драйверов развития экономики в провинциях, но теперь пытаются бороться.

В Индии вплоть до получения страной независимости (1949 г.) все банки были частными, но в 1955 г. началась национализация банковской системы, продолжающаяся по сей день. На сегодня государство контролирует 29 банков, что составляет примерно 75\% всех банковских активов Индии. При этом ставится цель расширения банковской деятельности и сокращения региональных диспропорций. Постановление правительства предписывает всем банкам при открытии одного филиала в развитом регионе открывать еще четыре филиала на периферии (обычно - в сельской местности). В результате такой политики количество филиалов за период с 1970 по 1990 гг. выросло с 1,8 до 35 тыс., было создано свыше миллиона рабочих мест, а кредитование стало доступно миллионам заемщиков. К 2016 г. филиальная сеть государственных банков выросла на 800\%. Данная политика помогла снизить экономические, социальные и политические барьеры между населением и государством ${ }^{6}$.

Резервный банк Индии, помимо выполнения функций центрального банка, выступает регулятором кредитных и инвестиционных потоков по отраслям и регионам, официально признанных стратегическими. Помимо «прорывных», такой статус в Индии получают те сферы, развитие которых в должной мере не обеспечивается рыночными силами экономики. С этой целью Резервный банк устанавливает кредитные лимиты, предписывающие банкам кредитовать приоритетные отрасли в определенном объеме от общей величины займов. Кроме этого для коммерческих

${ }^{6}$ Маляров О.В. Независимая Индия. Эволюция социально-экономической модели и развитие экономики. М., 2010. Книга 2. С. 602-638. 
банков устанавливаются нормы ликвидности, обязывающие их приобретать определенные активы, включая государственные ценные бумаги с низкой доходностью. Такие вложения используются с целью финансирования государственных инвестиций по приоритетным направлениям.

Для того чтобы обеспечить сбалансированную координацию финансовых потоков, проходящих через различные каналы финансово-кредитной системы Индии, правительство создало головные кредитные организации для основных сфер экономики: Индийский банк промышленного развития, Национальный банк для сельского хозяйства и сельского развития, Экспортно-импортный банк Индии, Банк развития мелкой промышленности, Национальный банк жилищного строительства, Индийская компания кредита и инвестиций в морское судоходство, Индийская компания финансирования туризма.

Региональную банковскую сеть формируют дочерние организации и филиалы государственных банков, которым вменено в обязанность обслуживание отстающих регионов. Кроме того, существует разветвленная сеть кооперативных банков, которые поделили рыночные ниши следующим образом: городские кооперативные банки выдают долгосрочные займы, в том числе - на нужды сельского хозяйства. На сельские кооперативные банки приходится около $50 \%$ кредитования сельского хозяйства и смежных с ним отраслей, при этом займы - средне- и краткосрочные.

Важной чертой и серьезной проблемой индийского банковского сектора можно назвать отсутствие у населения привычки пользоваться банковскими услугами - большинство операций совершается за наличный расчет, и потому государству трудно контролировать эти денежные потоки, поддерживая должный уровень финансово-налоговой ответственности у компаний и физических лиц [Маклакова, 2018]. Кроме того, по причине бедности населения в банковском секторе Индии накопился большой процент «плохих» долгов. Другая проблема заключается в том, что из-за высокой доли государственного капитала в банковском секторе практически отсутствует конкуренция, что дестимулирует финансовые организации в отношении их дальнейшего роста и развития, включая внедрение инноваций. 
На наш взгляд, из разностороннего зарубежного опыта повышения эффективности регионального банковского бизнеса в российских условиях могут оказаться полезными следующие меры:

1) курс на развитие специализации на уровне региональной сети - уход от универсальности и сосредоточение отдельных банков на оказании целевых услуг [Thai, 2015];

2) развитие филиальной сети для большего взаимодействия с населением.

\section{Выводы и заключение}

В Российской Федерации финансовые услуги наиболее широко доступны в городах-миллионниках, степень их проникновения снижается (порой - весьма драматично) по мере удаления от региональных и промышленных центров. Причинынезначительное и постоянно уменьшающееся количество банковских подразделений, ограниченный функционал платежных терминалов и недостаточно развитая инфраструктура по приему банковских карт.

Региональная банковская система имеет свои специфические условия функционирования, среди которых стоит выделить следующие:

- относительно низкая финансовая грамотность клиентов, как следствие - настороженное отношение даже к традиционным банковским услугам и крайне низкая заинтересованность в современных продуктах;

- отсутствие у клиентов стремления овладеть новыми способами получения услуг через удаленный доступ по интернетканалам и мобильный телефон;

- в отдельных случаях - отсутствие устойчивой интернетсвязи, что препятствует нормальному функционированию технологий удаленного доступа;

- неспособность небольших региональных банков конкурировать с крупными игроками, одновременно с ними внедрять новые банковские продукты и услуги (в том числе в онлайнплоскости);

Зачастую сотрудники региональных банков/офисов, даже при понимании всей этой специфики, не имеют возможности перестроить устоявшуюся в «столицах» бизнес-модель под их 
конкретный регион базирования. Лидирующие игроки рынка крупные консолидированные банки с большой долей государственного капитала - часто задают тон всей отрасли, и более мелкие кредитные организации вынуждены принимать решения под влиянием тех или иных импульсов государственной политики, а также более крупных банков. Показательный пример - цифровизация (диджитализация) отдельных низкорентабельных услуг.

Как показал наш опрос, в небольших поселениях переход на онлайн-банкинг осуществляется особенно тяжело, в связи с чем мы считаем нерациональным сокращение в них количества офисов и в целом - кредитных организаций.

На основе зарубежного и отечественного опыта можно назвать несколько мер, актуальных для развития регионального банкинга в России:

1) повсеместное повышение уровня финансовой грамотности населения и представителей бизнеса;

2) активное внедрение практики «мобильных офисов» для большего покрытия спроса на банковские продукты и услуги в удаленных малых поселениях;

3) не сокращение, а расширение региональной банковской сети, в том числе - с целью замещения неэффективных кредитных организаций, чья лицензия была отозвана Центральным банком;

4) уделение большего внимания, в том числе на государственном уровне, развитию регионального банкинга и обеспечению равного доступа населения к банковским услугам.

\section{Литература}

Журавлёва Т.Л., Леонов М.А. Банковская система России в последние годы: общий и региональный взгляд // Финансовый журнал. 2015. № 6. С. 47-58.

Клешко Д.В., Мусаев Р.А. Региональные банки: состояние и тенденции развития // Деньги и кредит. 2016. № 6. С. 58-63.

Клешко Д. В., Мусаев Р.А. Развитие системы рефинансирования банковского сектора России // Финансовый журнал. 2015. № 2. С. 42-51.

Кравец Л.Г., Потапова С.В. Подходы к оценке доступности банковских кредитных услуг и ее влияние на уровень финансовой стабильности банковского сектора // Вестник Саратовского государственного социально-экономического университета. 2016. № 1(65). С. 42-47.

Маклакова Ю.А. Роль ценностей в ведении банковского бизнеса в период кризиса // Научные исследования экономического факультета. Электронный журнал. Т. 8. Вып. 3. 2016. С. 25-34. 
Маклакова Ю.А Проблемы и перспективы банковского сектора Индии // Банковское дело. 2018. № 12. С. 38-42.

Convery, F., Dunne, L., Redmond, L., Ryan, L. Political Economy of Tradeable Permits - Competitiveness, Co-operation and Market Power// OECD Headquarters. 2003. P. 5.

Guiso, L. Does local financial development matter? // National bureau of economic research1050 Massachusetts Avenue Cambridge, MA 02138. Working Paper. 2002. № 8923. 45 p.

Fiorentino, E. The Effects of Privatization and Consolidation on Bank Productivity: Comparative Evidence from Italy and Germany // Deutsche Bundesbank Discussion Paper. 2009. № 3. 46 p.

Thai, K.S. Financing Small and Medium Enterprises in China: Recent Trends and Prospects beyond Shadow Banking // HKUST IEMS Working Paper. No. 24. 2015. 47 p.

Статья поступила 12.03.2019.

Для цитирования: Маклакова Ю.А. Проблемы функционирования банковской системы в регионах России и перспективы регионального развития на основе зарубежного опыта// ЭКО. 2019. № 8. С. 163-178. DOI: 10.30680/ ECO0131-7652-2019-8-163-178.

\section{Summary}

Maklakova, Y.A., Scientific Research Institute Under the Ministry of Finance, Economics Faculty of Moscow State University, Moscow

The Problems and Prospects of Regional Banking in Russia

Abstract. This work considers the social function of banking and development of regional banking in general without focusing on the definition of "regional bank", which is not defined in the Russian legislation. The author suggests that every region of Russia in which there is banking business should be treated as a separate element of the entire banking system. The ongoing digitalization aligns banking with the capabilities of the Central administrative region, failing to adapt it to the needs of regions. Such state policy is not effective as it implies a significant reduction in the number of banks. The author believes that transferring banking products and services online should not become a widespread practice and proposes recommendations for improving regional banks operation and development of a regional banking network based on domestic and international experience as well as the method of expert interviews. The main provisions and conclusions of the article may help government and bank managers, especially those involved in regional banks' management.

Keywords: regional banks; development of a regional banking network; international experience of regional banking; problems and prospects of the regions of Russia; financial literacy; digitalization; reduction of the banking sector

\section{References}

Zhuravleva, T.L., Leonov, M.A. (2015). Russian Banking System in Recent Years: General and Regional Perspectives. Finansovy zhurnal. No. 6. Pp. 47-58. (In Russ.). 
Kleshko, D.V., Musaev, R.A. (2016). Regional Banks: Condition and Development Trends. Den'gi I kredit. No. 6. Pp. 58-63. (In Russ.).

Kleshko, D.V., Musaev, R.A. (2015). Development of Refinancing System of the Russian Banking Sector. Finansovy zhurnal. No. 2. Pp. 42-51. (In Russ.).

Kravets, L.G., Potapova, S.V. (2016). Approaches to evaluation of bank loan accessibility and its impact on financial stability of the banking industry. Vestnik Saratovskogo gosudarstvennogo sotsial'no-ekonomicheskogo universiteta. No. 1 (65). Pp. 42-47. (In Russ.).

Maklakova, Yu.A. (2016). The role of values in the management of banking business in the crisis period. Nauchnye issledovaniya ekonomicheskogo fakul'teta. Elektronnyy gurnal. Tom 8. No. 3. Pp. 25-34. (In Russ.).

Maklakova, Yu.A. (2018). The problems and perspectives of the Indian banking sector. Bankovskoe delo. No. 12. Pp. 38-42. (In Russ.).

Convery, F., Dunne, L., Redmond, L., Ryan, L. (2003). Political Economy of Tradeable Permits - Competitiveness, Co-operation and Market Power. OECD Headquarters.P. 5.

Guiso, L. (2002). Does local financial development matter? National bureau of economic research1050 Massachusetts Avenue Cambridge, MA 02138. Working Paper. No.8923. 45 p.

Fiorentino, E. (2009). The Effects of Privatization and Consolidation on Bank Productivity: Comparative Evidence from Italy and Germany. Deutsche Bundesbank Discussion Paper.No.3. 46 p.

Thai, K.S. (2015). Financing Small and Medium Enterprises in China: Recent Trends and Prospects beyond Shadow Banking. HKUST IEMS Working Paper. No. 24. 47 p.

For citation: Maklakova, Yu.A. (2019).The Problems and Prospects of Regional Banking in Russia. ECO. No. 8. Pp. 163-178. (In Russ.). DOI: 10.30680/ECO01317652-2019-8-163-178. 